\title{
A convergência recente entre os setores brasileiros de comunicação de massa e de telecomunicações
}

\author{
João Martins Ladeira*
}

\begin{abstract}
Resumo
Análise da convergência, em nosso país, entre setores de telecomunicações e comunicação de massa audiovisual, por meio da economia política da comunicação e do conceito de empresa em rede. Desdobramento da segunda onda de globalização no segmento audiovisual nacional, a reorganização desta indústria cultural na última década ocorre por meio de participação acionária de corporações de telecomunicações em operações de TV por assinatura, cenário distinto do qual predominavam os oligopólios que historicamente controlaram o mercado brasileiro. Análise dos empreendimentos globais e das alianças estratégicas na aliança entre Globo e Telmex, na fusão entre Sky e DirecTV e na criação da Vivax e de sua incorporação a Net.

Palavras chave: Economia Política da Comunicação. Empresa em Rede. Estudos de Globalização.
\end{abstract}

The recent convergence between Brazilian mass communication and telecommunication sector

Abstract

Analysis about the convergence between telecommunication and audiovisual mass communication sectors in Brazil during the last decade through the political economy of communication and the network enterprise concept. The reorganization of this cultural industry, consequence of the second wave of globalization at the Brazilian audiovisual sector, occurs through shareholder participation of telecommunication corporations in paid television enterprises.

* Pós-doutorando Capes/PNPD do Programa de Pós-Graduação em Comunicação, Centro de Ciências da Comunicação, Universidade do Vale do Rio dos Sinos (Unisinos), São Leopoldo-RS, Brasil. Foi professor do curso de Comunicação Social da Universidade Estácio de Sá e professor substituto de sociologia na Faculdade de Direito da Universidade do Estado do Rio de Janeiro. Possui doutorado em sociologia pelo Iuperj e mestrado em Comunicação pela Universidade Federal Fluminense. E-mail: joaomartinladeira@gmail.com 
That experience can be considered as a different trajectory, compared with the oligopolies which traditionally dominated the Brazilian market. An analyze of global entrepreneurships and strategic alliances at the association between Globo and Telmex, the fusion between Sky and DirecTV, and the creation of Vivax, purchased by Net.

Keywords: Political Economy of Communication. Network Enterprises. Globalization Studies.

\section{La convergencia recenté entre los sectores brasileños de comunicación de masas e de telecomunicaciones}

\section{Resumen}

Análisis de la convergencia entre sectores de telecomunicaciones e comunicación de masa audiovisual, ocurrido en Brasil en la ultima década, a través de lo debate de la economía política de la comunicación e de la empresa en red. Consecuencia de la segunda onda de globalización en lo sector audiovisual, la reorganización dista industria cultural ocurrí por la participación accionaria de corporaciones de telecomunicación en operaciones de televisión paga, circunstancia distinta de los oligopolios que controlaran el mercado brasileño. Lo texto analiza los emprendimientos globales e las alianzas estratégicas en la asociación entre Globo e Telmex, la fusión entre Sky e DirecTV e la creación de Vivax e su compra por Net.

Palabras clave: Economía Política de la Comunicación. Empresa en Red. Estudios de Globalización.

\section{Introdução}

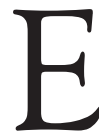

ste artigo analisa o processo recente de convergência entre os setores de telecomunicações e de comunicação de massa (especialmente o audiovisual) ocorrido no Brasil durante a última década. Para isso, toma como referência a discussão sobre economia política da comunicação (BOLAÑO, 2004) e o debate de Castells (1996) relativo à empresa em rede. Tal investigação se associa ao esforço de entender como se estabelecem dinâmicas de poder no interior das indústrias produtoras de cultura (MOSCO, 2009), na expectativa de compreender os enfrentamentos entre os diversos envolvidos no processo de definição e institucionalização de lógicas organizacionais para a exploração econômica num capitalismo contemporaneamente reformulado (BOLAÑO \& BRITTOS, 2007; CASTELLS, 2009; MORAES, 2010). 
Ao final da primeira década do século 21, pode-se argumentar que os últimos anos foram marcados pela intensa reorganização desta indústria cultural, desdobramento de uma segunda onda de globalização no segmento audiovisual nacional (RAMOS, 1997). Este movimento ocorre associado à dinâmica de globalização da propriedade destas indústrias (HELD ET AL, 1999). No período aqui discutido, percebe-se uma presença cada vez maior de corporações de telecomunicações na difusão de comunicação de massa, através especificamente de participação acionária em operações de televisão por assinatura. Trata-se de um cenário distinto daquele no qual predominavam os oligopólios que historicamente controlaram o mercado brasileiro. Tal fenômeno ocorre associado à tentativa de definir novas regras jurídicas para o setor audiovisual (possibilitando o surgimento de normas inéditas para a propriedade dos meios de comunicação, como o controle por grupos estrangeiros); de um intenso movimento de aquisições entre operadoras de televisão por assinatura; da abertura de capital e de negociações em bolsas de valores, indicando a existência de um conjunto coerente de transformações organizacionais.

Este texto discute a associação progressivamente maior entre estes dois setores, convergência que representa uma oportunidade para pensar os avanços no processo de reestruturação do capitalismo em relação às indústrias culturais. Trata-se tal tema recorrendo à explicação de Castells sobre os desdobramentos da reorganização produtiva por meio de parâmetros globais, expressa na necessidade dos oligopólios multinacionais e corporações locais adotarem um formato para suas relações que envolva associações até então inexistentes. Tais ligações decorrem da necessidade de integrar atividades de importância complementar para ambos os setores. Deste modo, interpreta-se tal internacionalização pela necessidade de administrar redes econômicas globais nas quais empresas brasileiras e estrangeiras são encaradas como nós diversos, englobando unidades de negócios regionalmente localizadas, mas globalmente conectadas. Logo, entendem-se tais operações como decorrência da necessidade de garantir o funcionamento da economia em tempo real, como uma unidade associada de empresas em rede. 
Compreende-se tanto a transformação global no modelo de regulação das telecomunicações quanto o conjunto de inovações tecnológicas voltadas à digitalização como os elementos que impulsionam este processo. Há duas décadas um setor nacionalmente controlado em países bem diferentes, tal indústria se transforma numa das atividades em que a lógica de regulação pelo mercado se encontra mais visível (MORAES, 2010; STRANGE, 1996). No caso brasileiro, dois acontecimentos parecem associados. O primeiro é o ciclo iniciado com a privatização do sistema Telebrás, desdobramento da tendência global acima citada, encerrando o período do controle por meio de monopólios estatais. Trata-se de um fenômeno estritamente ligado ao abandono do projeto nacional-desenvolvimentista (DINIZ \& BOSCHI, 2004). O segundo reside nas oportunidades tecnológicas surgidas pela difusão de inovações voltadas para a distribuição do audiovisual por meio de meios digitais, materializada na transmissão digital via cabo e satélite. Pensar todos estes temas se apresenta como um desafio relevante para o campo da comunicação, possível de ser abordado pelo referencial político-econômico, associado à discussão sociológica de Castells.

Este artigo está dividido em quatro partes. Na primeira, apresentam-se os referenciais teóricos da discussão. Na segunda, terceira e quarta, discute-se a reformulação contemporânea deste setor no Brasil: a associação entre Globo e Telmex, a fim de permitir a Net agir no mercado de telefonia e de comunicação; a fusão entre Sky e DirecTV, como um exemplo de empreendimento global com diversas consequências nacionais; e o desenvolvimento e a venda da Vivax, como indicativo das contradições para as alianças estratégicas de empresas em rede em nosso pais. Na conclusão, argumenta-se sobre o modo por meio do qual grupos tradicionais se esforçam para manter sua relevância, adequando-se às contingências de uma economia global.

\section{Referenciais teóricos: economia política da comunicação e empresa em rede}

Fruto da crítica à análise do imperialismo cultural e à teoria de dependência, a perspectiva da economia política da comunica- 
ção busca compreender a construção das dinâmicas de poder no interior das indústrias produtoras de bens culturais. Assim, versa sobre a organização dos modelos de regulação para a economia, pressupondo que sua estabilidade durante o tempo se vê continuamente frente à possibilidade de ruptura e reformulação a partir do surgimento de inovações tecnológicas e organizacionais. Daí, tem início a reorganização que vai gerar outra ordem, nos mesmos termos desta estabilidade temporária. A criação de oligopólios ou de mercados competitivos se sucede no tempo, como resultado das transformações que ocorrem a partir de processos de destruição criadora (BOLAÑO, 2004; BOLAÑO; BRITTOS, 2006).

Neste artigo, observa-se a alternância entre momentos de concorrência aberta e de concentração. Porém, é possível abordar o estabelecimento de oligopólios e a reintrodução da competição por um terceiro ponto de vista. Considerando as complexidades da organização social contemporânea e as contingências surgidas a partir da renovação técnica das forças produtivas, recorre-se à descrição empírica oferecida por Castells sobre as redes informacionais, tratando este terceiro modelo como uma possibilidade complementar à distinção entre oligopólios e livre concorrência. Desta maneira, pressupõe-se que a regulação da economia passa a depender de elementos relativos à flexibilidade e à abertura à transformação.

Aqui, usa-se a noção de empresa em rede com o interesse de compreender as características da reorganização recente do mercado de televisão. Em Castells, o tema da reformulação das corporações é parte de um assunto mais amplo: as transformações no modo de desenvolvimento e de produção. Tal debate atravessa um tema central: os novos arranjos político-econômicos que permitem a criação de um sistema informacional, sem reduzir a organização social às características das fontes de produtividade. Assim, supõe-se o surgimento de uma lógica informacional, da mesma forma que a produção centrada na indústria havia criado um modo de vida industrial.

A discussão sobre as redes informacionais é essencial em tal esforço. Conjuntos de nós conectados por meio dos recursos presentes numa renovação centrada no uso das tecnologias de infor- 
mação, tais ferramentas participam da geração de organizações e instituições adequadas ao funcionamento flexível e reprogramável do sistema econômico. A principal característica destas redes está na produção de instrumentos capazes de criar um mercado global, oferecendo novas possibilidades para obter produtividade numa organização industrial já madura (CASTELLS, 1996). Tais redes auxiliam na reorganização das estruturas produtivas, criando uma economia em tempo real.

Assim, a empresa em rede se caracteriza como um tipo de associação entre firmas compatível com as necessidades de uma nova economia. Por um lado, descende dos empreendimentos multinacionais, formato historicamente pioneiro para a corporação internacional. $\mathrm{O}$ modelo de Castells frisa a intensa dependência do território nacional no qual tais firmas atuam, deixando de lado o argumento sobre corporações transnacionais descoladas de contingências territoriais. Por outro, a empresa em rede representa um passo adiante em relação às multinacionais. Tal arrumação tem como marca a associação em formatos capazes de envolver associações internacionais de participação acionária em projetos de negócios, modelo mais complexo que o de atuação em bases nacionais diferenciadas.

O modelo de empresa em rede caracteriza-se em termos a) da produção flexível, b) da crise da grande corporação verticalmente integrada, c) da flexibilização na divisão do trabalho, d) das subcontratações entre firmas e e) das alianças estratégias corporativas. O primeiro tópico possui importância central: em decorrência da complexificação social contemporânea, surgem novos tipos de corporações, nas quais prevalece a crescente relevância da produção diversificada em contraposição aos produtos de massa obtidos pelos ganhos de escala presentes na manufatura em série, confeccionados por trabalho padronizado e controlados por empreendimentos de grande porte.

O segundo ponto indica a demanda crescente por um tipo específico de flexibilidade para a estrutura organizacional das firmas. Presente nos elos entre variadas empresas, trata-se de um padrão necessário tanto às grandes corporações quanto às pequenas e médias. Esta discussão sobre o declínio da integração vertical 
versa não sobre a redução do tamanho dos empreendimentos, mas sobre o imperativo de grandes e pequenas firmas se adequarem ao uso das redes. Efetivamente relevante é o modo de dominação constituído a partir destes instrumentos, indicando como a corporação de grande porte pode manter sua relevância exatamente por se adequar à lógica de tais redes ${ }^{1}$.

O tópico terceiro versa sobre a reformulação dos padrões de trabalho herdados do fordismo. Porém, a distribuição de tarefas no interior destas firmas, assim como a possibilidade de se tornarem mais flexíveis em comparação ao modelo pregresso não são o foco deste artigo. Ao mesmo tempo, o formato da subcontratação entre corporações parece ter importância secundária no debate aqui empreendido. Relevantes são as alianças estratégicas de grandes empresas (CASTELLS, 1996, p.176-178). Elas organizam de forma específica as redes de negócios globais para o setor brasileiro de televisão, estabelecidas em torno de determinados projetos, capazes de reunir corporações de diferentes partes do mundo pela necessidade de atuação inter-relacionada. Tal fenômeno decorre da possibilidade da grande empresa, especialmente, ter a capacidade de criar laços entre firmas dos mais diversos tipos. De fato, as operações de televisão por assinatura representam uma experiência inédita para os grandes grupos de comunicação audiovisual no Brasil no que se refere à associação com outras corporações internacionais. Tais problemas serão discutidos nas próximas seções.

\section{Convergência econômica entre operações de TV por assinatura e telecomunicações}

A partir de certo momento na década de 2000, os mercados de televisão por assinatura e de telecomunicações estabelecem relações de proximidade progressivamente maior, indicando a

\footnotetext{
${ }^{1}$ Buscar no mercado brasileiro de televisão qualquer aumento de relevância de pequenas firmas seria algo bastante discutível. Aqui, empresas de pequeno porte não possuem relevância: corporações de menor dimensão permanecem no mercado tempo suficiente para ser consolidadas por grandes grupos. $\mathrm{O}$ que não impede que tal processo ocorra exatamente a partir dos mecanismos típicos às empresas em rede, como se discute adiante.
} 
convergência econômica de ambos. No Brasil, acontecimento emblemático será a aliança entre Globo e Telmex em relação a Net. Anunciado em 06/2004, o negócio praticamente dividia a propriedade da corporação entre as duas corporações, com a expectativa da Telmex se tornar controladora após a alteração da legislação brasileira. Frente à necessidade de renegociar dívidas, a compra de parte do empreendimento por um grupo de outro setor garante, ao mesmo tempo, acesso ao mercado de telefonia local e de longa distância, unindo o negócio de comunicação ao de banda larga (POSSEBON, 2009, p.207-210).

A Telmex havia entrado no mercado brasileiro em 04/2004, com a compra da Embratel. Tal empresa fora posta à venda no âmbito do processo de falência da MCI, controladora do negócio desde o leilão do sistema Telebrás em 1998 (MOREIRA, 2004a; VALOR ECONÔMICO, 2004). Desta forma, a convergência aqui discutida se relaciona a uma decisão anterior: a transformação do modelo de regulação para as teles. A partir daí, as possibilidades deste mercado passam a ser exploradas a partir da operação conjunta de duas corporações centradas em atividades diferentes, cuja associação se mostra imprescindível para a participação de um grupo internacional, oriundo de outro setor econômico, no segmento de comunicação.

Processo de internacionalização da Net e a especialização da Globo na competência central da produção de conteúdo prossegue com a aquisição, em 10/2010, de outra parcela significativa da empresa de televisão paga. Por meio do mecanismo de Oferta Pública Voluntária, o objetivo da Telmex, pela ação da Embratel, seria alcançar até $100 \%$ das ações preferenciais da Net. Neste processo, a corporação de telecomunicações conseguiria adquirir $73 \%$ deste tipo específico de papel (EMBRATEL TELECOMUNICAÇÕES, 2010). Ao final do negócio, a Embratel passaria a ter $92,2 \%$ das ações preferenciais da Net. Assim, percebem-se firmas à procura de formatos de organização adequadas à presença em mercados baseados em tecnologia. A busca por diversificar atividades e reter clientes se apresenta como imperativo imediato, e a lógica pela qual ocorre é através da associação por alianças estratégicas e cooperação entre firmas. 
Tais aquisições certamente ampliam o tamanho das empresas, construindo em alguns casos operações gigantescas, presentes em diversos países. No entanto, a relevância das corporações de maior porte reside não apenas no seu tamanho ou nas possibilidades de obter ganhos de escala. As aquisições decorrem do imperativo de agregar produtos tecnologicamente relevantes, como a comercialização associada de mercadorias diversas, numa tentativa de diferenciação. Seu valor se afirma exatamente no momento em que se torna essencial a compra de tecnologias capazes de evitar a transformação dos produtos de tais corporações em commodities, como exemplo da necessidade de adequação a um paradigma informacional. $\mathrm{O}$ esforço de participar nesta lógica se dá pela concentração de negócios, que, entretanto, ocorre a partir de alianças estratégicas entre dois empreendimentos econômicos associados numa terceira operação. Um desdobramento desta mesma tendência será observado na seção posterior.

\section{Televisão por satélite e empreendimentos globais: a fusão Sky e DirecTV}

Saturado devido a razões técnicas e econômicas, o mercado de televisão aberta se vê frente à possibilidade de reorganização a partir da crescente importância da TV a cabo e via satélite. Inicialmente um negócio de porte limitado e restrito a cidades pequenas, o cabo se transforma, nos EUA, em uma atividade importante a partir da produção de conteúdo próprio, difundido ao largo das restrições impostas às grandes redes. Ao mesmo tempo, a transmissão via satélite torna-se uma oportunidade digna de nota devido ao aprimoramento de estruturas técnicas para transmissão de dados, utilizadas com o interesse de ampliar a presença em mercados estrangeiros, entre os quais se inclui a América Latina (DIZARD, 2000).

No Brasil, existiam em 2010 cerca de 9,8 milhões de assinantes de TV por assinatura, em diversas modalidades tecnológicas. A fatia relativa ao cabo se mantém como a mais importante; já a transmissão via satélite representa aproximadamente $41 \%$ do total (ABTA 2010). A despeito de possuir menor concentração 
de usuários, a televisão via satélite apresenta propriedades de intensa relevância para a discussão sobre alianças estratégicas. Aqui, a associação entre capital estrangeiro e nacional se torna importante desde o primeiro momento. Tentativas de introduzir serviços via satélite datam de 1991, com a comercialização de canais analógicos pela Globosat. Porém, apenas o aprimoramento técnico empreendido entre 1992 e 1993 pela News Corp, Hughes e PanAmSat permitirá a difusão de uma quantidade maior de sinais digitais (POSSEBON, 2009, p.80-82), definindo uma trajetória a ser seguida.

Tal operação complexa demanda uma tecnologia de custo elevado: devido à incapacidade de explorar isoladamente tal inovação, as corporações nacionais se vêem obrigadas a se associar com grupos internacionais. No Brasil, duas operações de TV via satélite entram em atividade a partir de 1996: a DirecTV e a Sky. A primeira era o resultado da associação de TVA, MVS Multivision, Cisneros e Hughes; a segunda, de Globo, News Corp, TCI e Televisa (POSSEBON, 2009, p.80-85, 167-168), num relacionamento entre grupos locais e internacionais com o objetivo de atuar num projeto de negócios específico. $\mathrm{O}$ início da atividade de ambas no Brasil corresponde a um tipo de aliança estratégica estabelecida e desfeita por meio dos mecanismos próprios ao capital financeiro, como no caso discutido na seção anterior, com o interesse de participar de mercados internacionais. Tais corporações mantém sua independência, a despeito da coexistência de suas atividades, indicando uma lógica de conexão própria às redes informacionais.

Durante suas atividades, as duas operações reuniriam dívidas significativas, devido às expectativas superdimensionadas sobre $\mathrm{o}$ potencial de crescimento do mercado brasileiro (MOLINA, 2006). A partir de certo momento, tais custos se tornam inviáveis para alguns. Em 05/1999, os 75\% da TVA sobre a operação brasileira e os $10 \%$ referentes à América Latina seriam comprados pela Hughes por US\$ 300 milhões (POSSEBON, 2009, p.167-168). $\mathrm{O}$ aumento de custos também seria percebido pelo sócio brasileiro da Sky. Elevados gastos com infra-estrutura contribuiriam como um dos principais fatores do endividamento: até 06/2003, os sócios da Sky teriam gasto US\$ 854 milhões; e a News Corp, 
US\$ 200 milhões, visando a arcar com dívidas da operação. Para a DirecTV, até 09/2004 os valores seriam de US\$ 840,4 milhões (CADE, 2004, p.7-8).

O endividamento não é específico ao mercado brasileiro. Nos EUA, o breve histórico da atividade tem como marca a falência da DirecTV em 03/2003. No final dos anos 90, a empresa havia adquirido diversas firmas de TV por satélite. Em 12/1998, compraria a USSB (United States Satellite Broadcasting) por US\$ 1,3 bi em dinheiro e ações (GRICE, 1998), incorporando programação economicamente relevante, como a do HBO, Movie Channel, Showtime, MTV, Nickelodeon e VH-1 (FABRIKANT, 1997). Em 01/1999, iria adquirir também a Primestar, segunda maior distribuidora de televisão por assinatura, por US $\$ 1,8$ bi (SANDEEP, 1999). Em 2002, a tentativa de compra da EchoStar seria barrada pelo órgão regulador dos EUA, alegando perda de competitividade para o setor (LABATON, 2002). Assim, a fusão de Sky e DirecTV relaciona-se a um movimento internacional de integração do negócio de TV por satélite. Em 04/2003, após a DirecTV norte-americana declarar concordata, a News Corp iria propor a aquisição de $34 \%$ das ações da rival (POSSEBON, 2009 , p. 203-5). O negócio seria concluído em 12/2003 (MOLINA, 2006).

Num mercado global, qualquer acordo internacional envolve consequências locais. No Brasil, a Anatel concederia anuência prévia à transação em 11/2003. No entanto, os negócios entre ambas ainda se manteriam separados por mais de um ano. Por fim, a união de ativos seria formalizada em 10/2004, evitando, porém, a fusão de operações. A aprovação pelo Cade ocorre em 05/2006 e a finalização da fusão, em 08/2006 (BASILE, 2004a, 2004b; MOREIRA, 2004b; VALOR ECONÔMICO, 2006). Ao mesmo tempo, o acordo envolveria a aquisição, pela News Corp, de $13,7 \%$ das ações então controladas pela Globo. Alegava-se a decisão da corporação brasileira em concentrar-se na competência estratégica de produção de conteúdo (CADE, 2004). Após a fusão, a marca Sky permaneceria ativa apenas no Brasil e no México. Em todos os demais países, DirecTV terminaria sendo a identificação adotada para o novo negócio. 
Tal ordenação entre as corporações teria, porém, duração limitada. Em 02/2007, a participação da News Corp seria comprada pela Liberty Media, num negócio que obrigaria as três corporações envolvidas a remodelar diversos negócios cruzados que possuíam. De um lado, a News Corp abriria mão de sua parte na DirecTV anteriormente adquirida. De outro, a Liberty Media retornaria sua parcela da News Corp. Os 16,3\% da News Corp de propriedade da Liberty seriam trocados pelos $38,4 \%$ da DirecTV detidos por aquele primeiro conglomerado, além de três redes regionais de esportes e US $\$ 550$ milhões. Ao fim da transação, a Liberty passaria a ter 40,4\% da DirecTV, tornando-se o maior acionista (FCC, 2008).

Consequências nacionais seriam o reposicionamento da Globo em termos da competência central da produção de conteúdo. Em 12/2010, a DirecTV iria adquirir, por US\$ 604,8 milhões, 18,9\% da participação do sócio brasileiro, exercendo o direito, previsto já no acordo de 2004, de ampliar sua participação no negócio. A Globo, porém, continuaria a atuar na programação do serviço e na produção de conteúdo. Proprietária, então, de $26 \%$ das ações da operação de satélite, a corporação brasileira passaria a ter apenas 7\% do total, contra os $93 \%$ sob responsabilidade da DirecTV. A decisão que permitiu tal ajuste previa a possibilidade dos papéis restantes serem comprados até 2014 (VALOR ECONÔMICO, 2010).

A entrada ou a saída de parceiros, a renegociação de prioridades e de papéis, a associação entre corporações com diversas competências, a globalização da propriedade econômica, tudo ocorre por meio de arranjos de negócios capazes de utilizar as capacidades de conexão e desconexão contidas nas ferramentas responsáveis pelo estabelecimento das empresas em redes. A segmentação de conteúdo e a tentativa de ir além da produção de massa, contida na expansão de canais para difusão de comunicação, dão-se por meio da adoção do multifuncionalismo obtido através da flexibilidade, num fenômeno interpretado como a crise da corporação verticalmente integrada. A importância de sócios estrangeiros se torna maior, devido aos investimentos necessários à trajetória tecnológica adotada. O resultado é a progressiva internacionalização do setor, fazendo com que os grupos que historicamente o controlavam busquem meios para manter sua importância. Porém, 
a despeito deste caráter internacional, a relevância das corporações locais não pode ser negada: este é o tema da próxima seção.

\section{Canbrás, Horizon, Vivax e Net: alianças estratégicas frente aos oligopólios}

A Vivax seria um exemplo de empresa nacional capaz de utilizar oportunidades de negociação e valorização típicas ao mercado financeiro. As licitações de 1997, momento inédito de disputa pública pelas outorgas do setor, se tornariam decisivas para a empresa vir a atuar. Ao contrario de 1988 e 1991, o mercado de televisão paga seria aberto dentro de um conjunto definido de regras institucionais (POSSEBON, 2009, p.136-158), permitindo a entrada de novos personagens. Independentemente dessas características, a corporação termina incorporada à estrutura de um dos oligopólios do setor, exemplo da contradição deste formato de capitalismo em nosso país. Entretanto, seu processo de compra consistiria num tipo de troca de ações, indicando o uso de mecanismos complexos, próprios a um mercado financeiro com significativo grau de organização.

A empresa surgiria da fusão entre duas operações de TV a cabo, Canbrás e Horizon, anunciada em 10/2003 e finalizada em 08/2004 (ANATEL, 2004a, 2004b). A Horizon fora instituída pela associação entre um investidor norte-americano que residia no Brasil e atuava numa empresa de tecnologia, um empresário de mineração e uma operadora norte-americana de TV por assinatura. Durante as licitações de 1997, esse grupo havia obtido licenças para o interior de São Paulo, região ainda pouco explorada pelos grandes grupos de TV paga. A Canbrás decorria da associação entre um personagem tradicional da comunicação de massa no Brasil, a Abril, com uma empresa de telecomunicações, a Bell Canadá, no interesse de explorar a região metropolitana e o litoral paulista. Esta segunda firma seria posta à venda em 2002 (POSSEBON, 2009).

Num curto período, a Vivax conseguiria abrir capital, expandir suas atividades e se tornar uma das maiores empresas de TV por assinatura do país. Suas ações começariam a ser vendidas em 
02/2006 (VIVAX, 2006a), numa oferta que renderia $\mathrm{R} \$ 529,2$ mi. No mesmo período, ela realizaria uma transação em debêntures no valor de R\$220 milhões (SISTEMA NACIONAL DE DEBÊNTURES, 2006). Por fim, a compra da empresa pela Net seria anunciada em 10/2006. A operação consistia de duas fases, a primeira tendo sido encerrada em 12/2006. Naquele momento, a Net compraria $36,7 \%$ de seus papeis através de troca de ações (VIVAX, 2006b, 2006c). A segunda fase receberia aprovação da Anatel em 05/2007 e do Cade em 12/2007 (CADE, 2006).

A Vivax havia sido um empreendimento econômico nascido a partir de uma possibilidade organizacional inédita: as outorgas públicas para o setor, distintas do processo pelo qual historicamente se disponibilizaram licenças para sua exploração. Tais oportunidades dependem de um mercado com um grau suficiente de organização para a entrada e saída de investidores. Tal fato termina por criar uma corporação de relevância significativa, que a despeito de seus resultados, acaba por ser incorporada pela aliança entre Globo e Telmex. Todavia, a compra pela troca de ações faz com que os antigos proprietários da Vivax permaneçam em atividade, num negócio que pode ocorrer apenas em circunstâncias nas quais estão disponíveis mecanismos desenvolvidos para a operação do capital financeiro.

\section{Conclusão}

mercado de televisão no Brasil vive um momento criado por condições político-econômicas novas e pela renovação tecnológica contida nas tecnologias digitais. Centrado no início dos anos 90 em torno do duopólio entre Globo e Abril, o segmento de TV por assinatura nesta última década tem sido marcado pela complexificação e pelo surgimento de novos personagens. Simultaneamente, estão em enfrentamento empresas de telecomunicações e operadoras de TV paga. Ambas as mercadorias são vendidas por corporações estabelecidas através de alianças estratégicas, num cenário que indica a convergência de negócios.

A tentativa de ampliar os limites convencionais da TV aberta e analógica passa pela diversificação da produção, na expectativa de ultrapassar o modelo do entretenimento de massa. Tal esfor- 
ço ocorre por meio de recursos disponíveis na organização das corporações em empresas em redes, conectadas em projetos de negócios pontuais. Nesta ligação, as associações proporcionadas pelos instrumentos típicos a mercados financeiros têm relevância essencial. A negociação em mercados de capitais e o uso de instrumentos públicos de aquisição em uma economia globalmente integrada são traços distintos dos empreendimentos familiares que dominaram o setor.

Entretanto, não se quer afirmar que tais corporações tenham perdido importância. Na verdade, ocorre exatamente o contrário. Estes grupos ampliam sua força à medida que dominam e utilizam as possibilidades contidas nas redes informacionais. Deste modo, o exemplo brasileiro representa um caso curioso de perda de relevância da grande corporação verticalmente integrada, que utiliza novos modelos de trajetórias organizacionais para reafirmar seu poder. Suas tentativas de negociar dentro de uma economia global foram o tema deste artigo, como exemplo das contradições de um tipo de inserção numa ordem internacional.

\section{Referências}

ABTA. Resultados Setoriais: TV por assinatura - operadoras. São Paulo: ABTA, 2010.

ANATEL. Horizon assume controle acionário da Canbrás, TV Mogno e TV Eucalipto. Brasília: Anatel, 2004a.

ANATEL. Anatel aprova compra da Canbrás pela Horizon e envia Ato de Concentração ao Cade. Brasília: Anatel, 2004b.

BASILE, Juliano. Cade determina congelamento da união da Sky com a DirecTV no Brasil. Valor Econômico, São Paulo, 15 abr. 2004a.

. Sky e DirecTV vão manter plataformas separadas. Valor Econômico, São Paulo, 20 out. 2004b.

BOLAÑO, César ; Valério BRITTOS. A televisão brasileira na era digital. São Paulo: Paulus, 2007.

BOLAÑO, César. Mercado Brasileiro de Televisão. 2.ed. São Paulo: PUCSP, 2004. 
CADE. Ato de Concentração n ${ }^{\circ}$ 53500.029160/2004. Brasília: Cade, 2004. Ato de Concentração n 53500.029599/2006. Brasília: Cade, 2006.

CASTELLS, Manuel. Communication power. Oxford: Oxford University Press, 2009.

. Rise of the network society. Oxford: Blackwell, 1996.

DINIZ, Eli; BOSCHI, Renato. Empresários, Interesses e Mercado: Dilemas do Desenvolvimento no Brasil. Belo Horizonte: Ed. UFMG, 2004.

DIZARD, Wilson. A Nova Mídia: A Comunicação de Massa na Era da Informação. Rio de Janeiro: Jorge Zahar, 2000.

EMBRATEL PARTICIPAÇÕES. Fato Relevante. Rio de Janeiro: Embratel, 2010.

F.C.C. Memorandum Opinion and Order. MB Docket No. 07-18. Washington, D.C: F.C.C, 2008.

FABRIKANT, Geraldine. Satellite TV Provider Waits for World to Catch Up. New York Times. New York, 03 nov. 1997. Disponível em <http://www.nytimes.com/1997/11/03/business/satellite-tv-provider-waits-for-world-to-catchup.html scp=2\&sq=DirecTV+USSB\&st=nyt $>$. Acesso em: 13 jan. 2010.

GRICE, Corey. Hughes buys satellite firm for $\$ 1.3$ billion. Cnet News, San Francisco, 14 dez. 1998. Disponível em: < http://news.cnet.com/Hughes-buyssatellite-firm-for-1.3-billion/2100-1033_3-219066.html?tag $=\mathrm{mncol}>$. Acesso em: 12 jan. 2010.

HELD, David; MCGREW, Anthony; GOLDBLATT, David \& PERRATON, Jonathan. Global Transformations: Politics, Economics, and Culture. Stanford: Stanford University Press, 1999.

LABATON, Stephen. F.C.C. Blocks EchoStar Deal With DirecTV. New York Times, New York, 11 out. 2002. Disponível em <http://www.nytimes. com/2002/10/11/business/fcc-blocks-echostar-deal-with-directv.html?scp=5\&sq=E choStar + DirecTV\&st=Search\&pagewanted=all $>$. Acesso em: 23 jan. 2010.

MOLINA, Matías. Como perder dinheiro na América Latina. Valor Econômico, São Paulo, 02 jun. 2006.

MORAES, Dênis de (org). Mutações do visível: da comunicação de massa à comunicação em rede. Rio de Janeiro: Pão e Rosas, 2010.

MOREIRA, Talita. Teles curtem ressaca depois de derrota para os mexicanos. Valor Econômico, São Paulo, 29 abr. 2004a. 
. Reestruturação avança com DirecTV e Sky juntas. Valor

Econômico, São Paulo, 13 out. 2004b.

MOSCO, Vincent. The political economy of communication. New York: Sage, 2009.

POSSEBON, Samuel. TV por Assinatura: 20 Anos de Evolução. São Paulo: ABTA, 2009.

RAMOS, Murilo. A Segunda Onda de Globalização na TV Brasileira. In: MORAES, Dênis de (org.). Globalização, mídia e cultura contemporânea. Campo Grande: Letra Livre, 1997.

SANDEEP, Junnarkar. DirecTV to buy rival Primestar's assets. Cnet News, San Francisco, 22 jan. 1999. Disponível em < http://news.cnet.com/DirecTV-to-buyrival-Primestars-assets/2100-1033_3-220509.html>. Acesso em: 13 jan. 2010.

SISTEMA NACIONAL DE DEBÊNTURES. Vivax registra segunda emissão no SND. 2006. Disponível em http:/www.debentures.com.br/informacoesaomercado/noticias.asp? mostra $=2848$. Acesso em: 20 jan. 2010.

STRANGE, Susan. The retreat of the state: the diffusion of power in the world economy. Cambridge: Cambridge University Press, 1996.

VALOR ECONÔMICO. Longa distância- A Embratel, da privatização à Telmex. Valor Econômico, São Paulo, 29 abr. 2004.

VALOR ECONÔMICO. Sky conclui fusão. Valor Econômico, São Paulo, 28 ago. 2006.

VALOR ECONÔMICO. DirecTV aumenta fatia. Valor Econômico, São Paulo, 16 dez. 2010.

VIVAX. Convite. Americana: Vivax, 2006a. Disponível em < http://www.acionista.com.br/home/vivax/080206_cerimonia.htm >. Acesso em: 19 jan. 2010.

VIVAX. Fato Relevante. Americana: Vivax, 2006b. Disponível em < http:// www.acionista.com.br/home/vivax/061206_fato_relevante.pdf $>$. Acesso em: 19 jan. 2010.

VIVAX. Fato Relevante. Americana: Vivax, 2006c. Disponível em < $\underline{\text { http:// }}$ www.acionista.com.br/home/vivax/131006_fato_relevante.pdf $>$. Acesso: em 19 jan. 2010.

Recebido: 16.09 .2010

Aceito: 05.05.2011

Intercom - RBCC

São Paulo, v.34, n.2, p. 219-235, jul./dez. 201। 
